\title{
REVIEW
}

\section{Hepatic stellate cells: role in microcirculation and pathophysiology of portal hypertension}

\author{
H Reynaert, M G Thompson, T Thomas, A Geerts
}

Gut 2002;50:571-581

Accumulating evidence suggests that stellate cells are involved in the regulation of the liver microcirculation and portal hypertension. Activated hepatic stellate cells have the necessary machinery to contract or relax in response to a number of vasoactive substances. Because stellate cells play a role in both fibrosis and portal hypertension, they are currently regarded as therapeutic targets to prevent and treat the complications of chronic liver disease.

See end of article for authors' affiliations

Correspondence to:

$\mathrm{H}$ Reynaert, Department of Gastroenterology-Hepatology University Hospital Free University of Brussels (AZ-VUB), Laarbeeklaan 101, B-1090 Brussels, Belgium;

Hendrik.Reynaert@

az.vub.ac.be

Accepted for publication 17 July 2001

\section{SUMMARY}

Portal hypertension is the result of augmented intrahepatic vascular resistance and increased portal blood flow. For many years it has been accepted that hepatic stellate cells play a key role in hepatic fibrosis. Accumulating evidence from in vitro and in vivo studies suggests that stellate cells are also involved in the regulation of the liver microcirculation and portal hypertension. Activated hepatic stellate cells have the necessary machinery to contract or relax in response to a number of vasoactive substances. Although contractile mechanisms are not as well studied as in skeletal or smooth muscle cells, recent studies have demonstrated that some intracellular signalling pathways and proteins involved in muscle contraction (for example, intracellular $\mathrm{Ca}^{2+}$ or rho) also exist in hepatic stellate cells. Because stellate cells play a role in both fibrosis and portal hypertension, they are currently regarded as therapeutic targets to prevent and treat the complications of chronic liver disease.

\section{INTRODUCTION}

According to Ohm's law $(\Delta \mathrm{P}=\mathrm{Q} \times \mathrm{R})$, portal venous pressure is proportional to blood flow and resistance: $\Delta \mathrm{P}$ is the change in portal pressure along the vessel, Q is portal blood flow, and R is the resistance to flow. ${ }^{1}$ In the normal liver, intrahepatic resistance changes with variations in portal blood flow, thereby keeping portal pressure within normal limits. In hepatic cirrhosis however, intrahepatic resistance and splanchnic blood flow are increased. Portal hypertension is thus the consequence of a combination of decreased compliance and increased portal blood flow.

The initial event in the pathophysiology of portal hypertension is increased vascular resistance to portal flow, primarily caused by structural changes such as fibrotic scar tissue and regenerative nodules compressing portal and central venules. Furthermore, it has been shown that swelling of hepatocytes and capillarisation of hepatic sinusoids (loss of endothelial fenestrations and collagen deposition in the space of Disse) are part of the increased vascular resistance. Increased blood flow in the portal vein occurs in a more advanced stage of portal hypertension and contributes to its maintenance and aggravation. Increase in portal inflow results from hyperdynamic circulation in the splanchnic and systemic blood vessels, which is characterised by increased cardiac output, reduced mean arterial pressure, reduced systemic vascular resistance, and expanded plasma volume. Although structural changes are most important in intrahepatic vascular resistance, it has become clear in the past years that not only fixed, but also variable, factors contribute significantly to the increased hepatic vascular resistance. ${ }^{2}$ It has been demonstrated that intrahepatic vascular resistance can be reduced by $20-30 \%$ with pharmacological agents. ${ }^{23}$ Several ultrastructural and physiological features of hepatic stellate cells (HSC) are similar to pericytes in other organs, suggesting that HSC may function as liver specific pericytes. Indeed, both the anatomical location of HSC and the capacity to contract or relax in response to various vasoactive mediators suggest that these cells may play a role in modulating intrahepatic vascular resistance and blood flow at the sinusoidal level. ${ }^{4-6}$ Several investigators have shown that activated HSC contract in response to various agents of which endothelin-1 (ET-1) is the strongest, and that some agents-for example, nitric oxide (NO)-promote relaxation of HSC. Moreover, HSC play a key role in the development of hepatic fibrosis, the main cause of portal hypertension. $^{7}$ The aim of this review is to summarise data on HSC contractility, their potential role in the liver microcirculation, and the pathophysiology of portal hypertension.

\section{HEPATIC STELLATE CELLS}

HSC represent $5-8 \%$ of all human liver cells and $13 \%$ of the volume of sinusoidal cells. Stellate cells

Abbreviations: ANP, atrial natriuretic peptide; $C A M P$, cyclic adenosine monophosphate; cGMP, cyclic guanosine monophosphate; $\left[\mathrm{Ca}^{2+}\right]_{i}$, intracellular $\mathrm{Ca}^{2+} ; \mathrm{DAG}$,

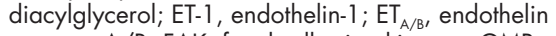
receptor $A / B$; FAK, focal adhesion kinase; $C G M P$, cyclic guanosine monophosphate; $\mathrm{HO}$, haeme oxygenase; HSC, hepatic stellate cells; IP3, inositol 1,4,5-trisphosphate; LPA, lysophosphatidic acid; PA, phosphatidic acid; NO, nitric oxide; NOS, nitric oxide synthetase; MLC, myosin light chain; PI(3)K, phosphatidylinositol 3-kinase; PIP2, phosphatidylinositol 4,5-bisphosphate; PLC, phospholipase C; PLD, phospholipase D; PKC, protein kinase C; ANGII, angiotensin II; ATI, type 1 angiotensin receptor. 
are located in the perisinusoidal space of Disse beneath the endothelial barrier. They have long cytoplasmic processes which run parallel to the sinusoidal endothelial wall. Second order branches sprout out from the processes, embrace the sinusoid, and penetrate between hepatocytes reaching neighbouring sinusoids. Some HSC are in close contact with nerve endings, some of which contain neuropeptides such as substance P, neuropeptide $Y$, somatostatin, and calcitonin gene related peptide. ${ }^{89}$

\section{"Hepatic stellate cells represent $5-8 \%$ of all human liver cells"}

In normal liver, HSC are mainly involved in the storage of vitamin A. In addition, they synthesise extracellular matrix components, matrix degrading metalloproteinases, cytokines, and growth factors. ${ }^{10}$ Following acute or chronic liver injury, HSC are activated and undergo a process of transdifferentiation leading to a myofibroblastic phenotype. Activated cells are characterised by loss of vitamin A droplets, increased proliferation, release of proinflammatory, profibrogenic, and promitogenic cytokines, migration to sites of injury, increased production of extracellular matrix components, and alterations in matrix protease activity providing the fundamental needs for tissue repair. In acute or self limited liver damage, these changes are transient whereas in the case of persistent injury they lead to chronic inflammation and accumulation of extracellular matrix resulting in liver fibrosis and ultimately cirrhosis. Several growth factors and cytokines are involved in HSC activation and proliferation, of which transforming growth factor $\beta$ and platelet derived growth factor are probably the most important. ${ }^{7}$

Furthermore, activated HSC express the smooth muscle $\alpha$ actin gene. In the branching processes, $\alpha$ smooth muscle actin and desmin filaments are present. Both the three dimensional structure and some of the ultrastructural characteristics are similar to pericytes, regulating blood flow in other organs. Hence HSC are currently considered to exert pericyte functions in the hepatic sinusoid.

\section{ROLE OF HEPATIC STELLATE CELLS IN REGULATING BLOOD FLOW IN NORMAL LIVER}

The liver is a richly perfused organ receiving approximately $25 \%$ of the cardiac output. About $75 \%$ of hepatic blood flow (rich in nutrients but poorly oxygenated) is supplied by the portal vein. The remainder of the blood supply (oxygen rich) is provided by the hepatic artery. The intrahepatic vasculature is composed of portal venules, hepatic arterioles, lymphatics, hepatic sinusoids, and central venules. Most blood enters the sinusoids from portal venules through inlet sphincters. Branches of hepatic arterioles terminate in sinusoids near their origin from portal venules (arterio-sinus twigs).

\section{"Data indicate that HSC may play a role in blood flow regulation in the normal liver"}

Furthermore, intersinusoidal sinusoids connect neighbouring sinusoids and finally sinusoids receive blood from arterioportal anastomoses via portal venules. Sinusoids drain their blood in central venules through outlet sphincters. ${ }^{11}{ }^{12}$ The hepatic sinusoid, which is the principal site of blood flow regulation, is the narrowest vascular structure within the liver; the highest vascular resistance occurs in the sinusoids. ${ }^{13}$ Moreover, it is the vital site for transvascular exchange between blood and hepatocytes. The sinusoidal surface of the hepatocytes is separated from blood by fenestrated sinusoidal endothelial cells lining the sinusoid, Kuppfer cells (liver macrophages) protruding into the lumen of the sinusoid, Pit cells (liver specific natural killer cells) and HSC, also referred to as
Ito cells, lipocytes, fat storing cells, or hepatic perisinusoidal cells. ${ }^{8}$ From the above it is clear that there are several potential sites for sinusoidal blood flow regulation: (i) portal venules, (ii) hepatic arterioles, (iii) central venules, and (iv) sinusoids, with inlet sphincters, outlet sphincters, and sinusoidal cells of which HSC and sinusoidal endothelial cells have contractile properties. Data indicate that HSC may play a role in blood flow regulation in the normal liver.

The first direct evidence was provided by in vivo microscopy in normal rat liver. ${ }^{14-18}$ Infusion of ET- 1 in the portal vein caused a marked decrease in sinusoidal diameter and an increase in sinusoidal pressure gradient and resistance. ET- 1 was found to induce significant sinusoidal constriction at the sites of HSC but not at the sites of Kupffer cells or sinusoidal endothelial cells. Coadministration of L-NAME and an endothelin receptor $\mathrm{B}\left(\mathrm{ET}_{\mathrm{B}}\right)$ agonist resulted in significant bulging of HSC into the sinusoidal lumen and reorganisation of fat droplets in the cell body in a way consistent with shape changes accompanying cell contraction. ${ }^{19}$ Recently, some evidence was obtained that locally produced carbon monoxide might control sinusoidal blood flow in normal liver. Carbon monoxide is produced by degradation of haeme, mediated by the activity of haeme oxygenase (HO), and upregulates cyclic guanosine monophosphate (cGMP) thereby causing smooth muscle relaxation. Three isoforms of $\mathrm{HO}$ have been described: (i) HO-1, the inducible form (ii) HO-2, the constitutive form, and (iii) HO-3, a form with a low catalytic activity. ${ }^{20}$ Isoforms HO- 1 and HO-2 are expressed in the liver: HO- 1 in Kupffer cells and HO-2 in hepatocytes. ${ }^{21}$ Inhibition of endogenously produced carbon monoxide promoted sinusoidal contraction at sites that colocalised with HSC, suggesting that these cells may be the target of the relaxing effect of carbon monoxide. ${ }^{22}$ Even though these observations are suggestive, they do not prove that HSC modulate hepatic blood flow. Indeed, it has been shown that ET-1 induced presinusoidal sphincter constriction resulting in decreased sinusoidal blood flow without stellate cell contraction. ${ }^{23}$ This raises the question of whether sinusoidal diameter narrowing is not related to passive recoil of sinusoids secondary to decreased sinusoidal blood flow. In fact, experimental clamping of the portal vein has been shown to result in passive recoil of sinusoids and portal venules. ${ }^{24}$ Discrepant results are probably related to different doses of ET-1 and a different morphological method of assessing vessel diameter after tissue fixation of isolated perfused livers. ET-1 probably has sinusoidal as well as extrasinusoidal sites of action but the sinusoidal sites appeared to be sensitive to lower more physiological concentrations of ET- $1 .{ }^{17}$

In vitro experiments are also controversial. It has been demonstrated that HSC, cultured for 24 hours, relaxed in response to interleukin $\mathrm{I}^{25}$ and contracted in response to substance P and ET- $1 .{ }^{26}{ }^{27}$ Higher concentrations of ET-l were required to obtain a significant increase in intracellular $\mathrm{Ca}^{2+}$ $\left(\left[\mathrm{Ca}^{2+}\right]_{\mathrm{i}}\right)$ and contraction of HSC cultured for one day than of activated HSC. ${ }^{27}$ However, these observations could not be confirmed by other investigators. ${ }^{28}{ }^{29}$ Possible explanations for discrepant findings include damaging of receptors by isolation of cells and differences in the set up of contraction experiments. Indeed, although quiescent HSC may not possess the necessary machinery required for forceful contraction, weaker contractions might occur. To show collagen lattice contraction, a more forceful contraction of cells is required than the force needed to demonstrate contraction of isolated cells using phase contrast microscopy. Arguments against contraction of HSC in normal liver include: (i) HSC do not have a stellate shape but rather a spider-like shape which is unlikely to be contraction ready, (ii) effective contraction is limited by spatial constraint in the space of Disse and contraction would be possible only by cells with a powerful contractile machinery, and (iii) the presence of lipid droplets prevents microfilament assembly into a long span. ${ }^{30}$ Taken together, although some arguments are against, 
most evidence suggests that HSC are involved in the regulation of sinusoidal tone and blood flow in normal liver.

\section{CONTRACTILE APPARATUS OF ACTIVATED STELLATE CELLS.}

Actin microfilaments are a major component of the skeletal framework that determines cell shape. In addition, actin and myosin filaments form together the contractile apparatus of cells. In each case, in addition to the major proteins involved, there are many other proteins whose binding modulates the behaviour of these cell components. It must be stated that the information regarding the proteins involved in these complexes in stellate cells is negligible and that only assumptions can be made by analogy with smooth muscle cells which have some resemblance to activated stellate cells.

The components of all contractile apparatus are the thin actin filaments and the thick myosin filaments. Actin filaments are formed by polymerisation of actin monomers on a tropomyosin backbone. The actin filament lengths are determined by attachment of "capping" proteins such as tropomodulin which in fact bind to tropomyosin and prevent further extension. In muscle there are cytoskeletal and contractile actin filaments that are distinguished by different isoforms of both tropomyosin and actin.

The key to contraction is the shielding and unshielding of the myosin binding site on actin which at rest is blocked by tropomyosin (fig 1). The process is well understood in skeletal muscle where troponin binds to tropomyosin to modulate its position on the actin filament. Calcium binding to troponin causes movement of tropomyosin to expose the myosin binding site on actin to which myosin then binds, activating the actomyosin ATPase and giving rise to muscle contraction. ${ }^{31}$ The mechanism in smooth muscle is much less clear. It appears that the same isoforms of actin and tropomyosin are involved in the contractile elements of smooth muscle. Hence it is reasonable to suppose that tropomyosin will block the myosin binding site on actin as in skeletal muscle. This leads to the expectation that a mechanism for moving tropomyosin to expose the myosin binding site must also exist in smooth muscle.

In smooth muscle, phosphorylation of the regulatory light chain subunit of myosin is sufficient for contraction. However, contraction can occur without light chain phosphorylation. There is no simple relationship between the extent of phosphorylation and the force developed. Smooth muscle can remain tonically contracted with very little energy expenditure with a reduced rate of cross bridge cycling and ATP hydrolysis. ${ }^{32}$ It appears that a small number of high affinity myosin-actin cross bridges, possibly phosphorylated, switch actin filaments into a state that activates cross bridge cycling. The binding of each high affinity cross bridge switches adjacent actin monomers causing additional cross bridges. Tropomyosin enhances this effect by increasing the number of actin monomers that switch as a unit. Therefore, actin filaments and their associated binding proteins, tropomyosin, caldesmon, and calponin, have a major role in the contraction process in smooth muscle.

Tropomyosins have two major variants: short forms of 248 amino acids that are found in cytoskeletal actin filaments and long forms of 284 amino acids that are found in contractile actin filaments of muscle. There is great potential for isoform variation by variable splicing of the tropomyosin genes. The secondary and tertiary structure of the proteins is highly conserved (even from yeast to mammals) but there is potential for important functional changes from the splicing of alternative exons available in each of the genes. This is likely to affect binding to actin and the binding of regulatory proteins to tropomyosin.

The two main candidate proteins for the important role of modifying the tropomyosin binding conformation with actin
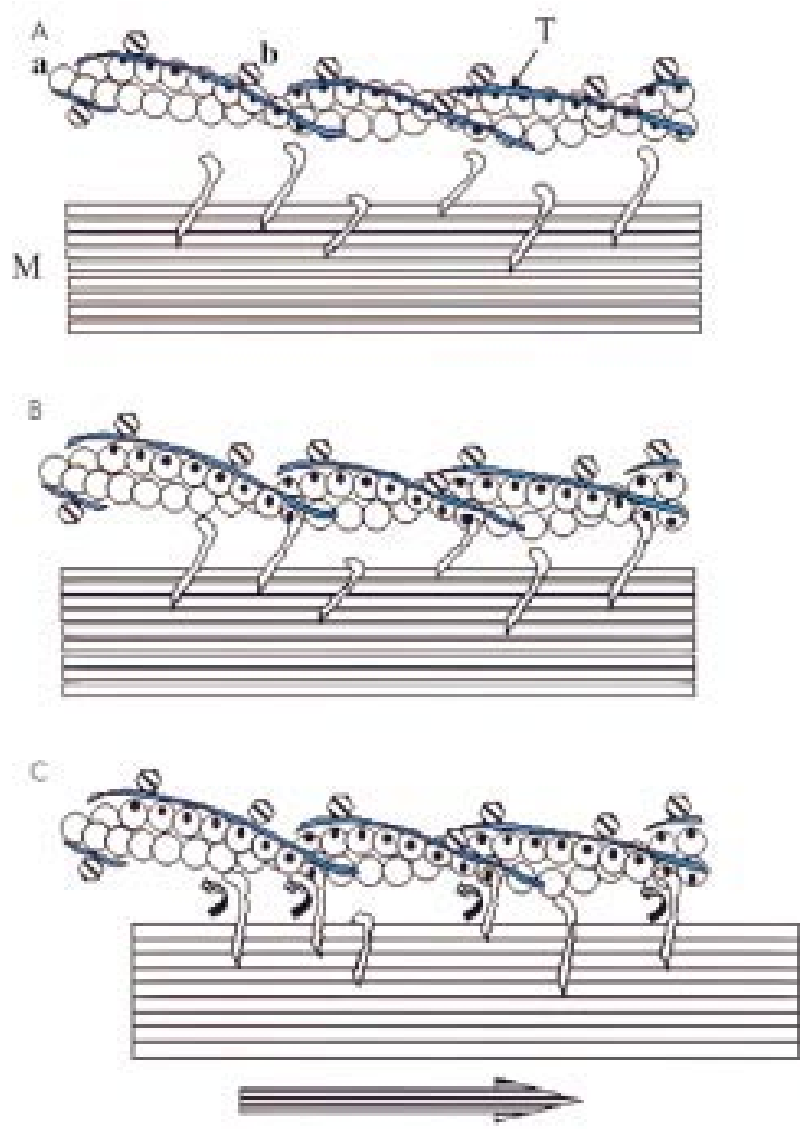

Figure 1 (A) Thin actin filament (a) and thick myosin filament (M) at rest, with tropomyosin $(T)$ covering the myosin binding site and binding proteins with tropomyosin (b). In skeletal muscle, $b$ is troponin; in smooth muscle it is likely to be calponin or caldesmon. (B) Activation of actomyosin: tropomyosin moves from myosin binding sites on actin in two stages - in skeletal muscle, stage 1 is caused by calcium binding to troponin while in smooth muscle stage 1 can be caused by myosin phosphorylation but that is not obligatory. In both cases initial myosin binding causes cooperative conformational changes in stage 2 to fully expose the actin binding sites for myosin. (C) Resulting actomyosin ATPase gives energy for a conformational change in myosin that moves the thick filament relative to the actin thin filament.

molecules in thin filaments are caldesmon and calponin. ${ }^{33}$ Caldesmon has two isoforms and the higher molecular weight variant of $150 \mathrm{kDa}$ is found associated with tropomyosin in actin filaments of smooth muscle. In the presence of tropomyosin, caldesmon can inhibit actomyosin ATPase activity. This ability is modulated by phosphorylation of caldesmon. Differentiated smooth muscle cells show transcriptional upregulation of caldesmon and tropomyosin. In addition, isoform changes in caldesmon and tropomyosin by alternative splicing are completely coordinated with the phenotype of smooth muscle cells. ${ }^{34}$ The site for calcium dependent regulation of actin-myosin interaction resides in the $\mathrm{COOH}$ terminal domain of both the low and high molecular weight forms. However, the high molecular weight form is expressed in differentiated smooth muscle cells whereas this is replaced by the low molecular weight isoform during dedifferentiation.

Three isoforms of the tropomyosin and actin binding protein calponin have been identified. Neutral calponin is found in the cytoskeleton bound to tropomyosin in actin filaments. ${ }^{35}$ Basic calponin is found in the actin filaments of the contractile elements of smooth muscle and has been used as a marker of smooth muscle phenotype. Cells expressing neutral calponin spread more efficiently than those expressing basic calponin and the latter also show reduced cell motility in 
Table 1 Agents influencing hepatic stellate cell contractility

\begin{tabular}{|c|c|c|}
\hline Agent & Effect & $\begin{array}{l}\text { Proposed } \\
\text { mechanism }\end{array}$ \\
\hline Endothelin-1 & Contraction & {$\left[\mathrm{Ca}^{2+}\right]_{\mathrm{i}}$} \\
\hline Thrombin & Contraction & {$\left[\mathrm{Ca}^{2+}\right]_{\mathrm{i}}$} \\
\hline Angiotensin II & Contraction & {$\left[\mathrm{Ca}^{2+11}\right.$} \\
\hline Vasopresssin & Contraction & {$\left[\mathrm{Ca}^{2+}\right]_{\mathrm{i}}$} \\
\hline Adenosine & Contraction & {$\left[\mathrm{Ca}^{2+}\right]_{i} ?$} \\
\hline Substance $P$ & Contraction & {$\left[\mathrm{Ca}^{2+}\right]_{\mathrm{i}}$} \\
\hline Leukotriene $D_{4}$ & Contraction & {$\left[\mathrm{Ca}^{2+}\right]_{\mathrm{i}}$} \\
\hline $\mathrm{PGF}_{2} /$ thromboxane & Contraction & {$\left[\mathrm{Ca}^{2+}\right]_{\mathrm{i}}$} \\
\hline Lysophosphatidic acid & Contraction & Rho kinase \\
\hline NO & Relaxation & cGMP \\
\hline ANP & Relaxation & cGMP/[Ca $\left.{ }^{2+}\right]_{i}$ \\
\hline Adrenomedullin & Relaxation & cAMP \\
\hline Somatostatin & Relaxation & $\begin{array}{l}{\left[\mathrm{Ca}^{2+}\right]_{i} / \text { rho }} \\
\text { kinase? }\end{array}$ \\
\hline Agents increasing cAMP/cGMP & Relaxation & cAMP/cGMP \\
\hline $\mathrm{PGI}_{2} / \mathrm{PGE}_{2}$ & Relaxation & CAMP \\
\hline Y-27632 (rho kinase inhibitor) & Relaxation & Rho kinase \\
\hline
\end{tabular}

PG, prostaglandin; NO, nitric oxide; $A N P$, atrial natriuretic peptide.

wound healing. Acidic calponin is particularly expressed in neurite outgrowths. So far, acidic calponin has not been demonstrated in smooth muscle cells. ${ }^{35}$ Calponin inhibits actomyosin ATPase activity and actin filament movement in vitro. Calponin inhibition of the actin-myosin interaction can be blocked by protein kinase C (PKC) mediated phosphorylation of serine-175. ${ }^{36}$

Although protein kinases have a role in cell signalling related to actin filaments, the final signalling pathway to the controlling actin filament proteins remains unclear. Furthermore, expression of the proteins discussed above is unknown in stellate cells together with how such factors as isoform expression vary during activation. Different isoform expression can be predicted to have a major effect on their behaviour.

\section{CONTRACTILITY OF HEPATIC STELLATE CELLS: INTRACELLULAR SIGNALLING}

Recent years have seen considerable progress towards understanding the signalling mechanisms regulating contraction in both muscle and non-muscle cell types. Studies to date have elucidated two major pathways: (i) $\mathrm{Ca}^{2+}$ signalling, which appears to predominate in smooth muscle, and (ii) the low molecular weight GTPase, rho pathway, which seems to exert the major controlling influence in non-muscle cells. ${ }^{37} 38$

\section{"To date, a number of agents which elicit either HSC contraction or relaxation have been identified"}

At present, it is not clear which of these pathways predominates in HSC although it has recently been suggested that as stellate cells become activated $\mathrm{Ca}^{2+}$ signalling pathways take on a more important role. ${ }^{39}$ Regardless of which pathway predominates, there is already sufficient evidence to demonstrate that both make important contributions and, as a result, this review will summarise data from HSC, muscle, and nonmuscle cell types. To date, a number of agents which elicit either HSC contraction or relaxation have been identified (table 1). In fig 2, intracellular pathways of contraction and relaxation are summarised.

\section{Mechanisms of contraction Phosphoinositidase C}

Activation of phosphoinositidase C, often referred to as phospholipase C (PLC), results in the hydrolysis of phosphatidylinositol 4,5-bisphosphate (PIP2) and the production of inositol 1,4,5-trisphosphate (IP3) and diacylglycerol (DAG). IP3 elevates $\left[\mathrm{Ca}^{2+}\right]_{\mathrm{i}}$ by releasing $\mathrm{Ca}^{2+}$ from intracellular stores and DAG activates PKC. Thus the hydrolysis of PIP2 generates two important second messengers: calcium and PKC. ${ }^{40}$

(i) Calcium is elevated either through hydrolysis of inositol lipids (as described above) or by entry through receptor/ voltage gated channels in the plasma membrane. Contractile agents have been demonstrated to elicit inositol lipid hydrolysis in HSC suggesting a role for this signalling pathway in HSC contraction. ${ }^{5}{ }^{41}$ In addition, a recent study has demonstrated that activation of HSC is associated with both upregulation of $\mathrm{L}$ type voltage operated $\mathrm{Ca}^{2+}$ channels that mediate $\mathrm{Ca}^{2+}$ influx and $\mathrm{KCl}$ induced contraction. ${ }^{42}$ However, as HSC have not been shown to be excitable, it will be important to establish the physiological relevance of these channels. It has been assumed that $\mathrm{Ca}^{2+}$ signalling pathways play an important role in mediating the contractile force generated by HSC in a similar manner to that shown in smooth muscle. ${ }^{43}$ Elevation of $\left[\mathrm{Ca}^{2+}\right]_{\mathrm{i}}$ elicits $\mathrm{Ca}^{2+} /$ calmodulin dependent activation of myosin light chain (MLC) kinase (see below) and dissociation of caldesmon from the actin-caldesmon-tropomyosin-myosin fibrillar domain which results in cycling cross bridge formation between actin and phosphorylated light chains of myosin. It has been demonstrated that reductions in HSC area, a marker of contractile force generation, correlate with the height of the $\left[\mathrm{Ca}^{2+}\right]_{\mathrm{i}}$ peak. ${ }^{44}$ However, many measurements of contraction are made 5-6 hours after agonist addition and it is therefore important to consider mechanisms which may regulate sustained contraction. In smooth muscle, the initial and sustained phases of contraction are mediated by different cellular and molecular events. The height of the $\mathrm{Ca}^{2+}$ transient correlates not only with the peak rise in MLC phosphorylation (see below) but also PKC association with the plasma membrane. ${ }^{45}$ This latter component has not been assessed in HSC

(ii) Activation of PKC in smooth muscle by phorbol ester results in a slowly developing and sustained contractile response. ${ }^{46}$ The time of initiation is shortened, rate of rise in tension is increased, and the magnitude of response is enhanced by agents (for example, ionomycin) that increase $\mathrm{Ca}^{2+}$ influx. Moreover, in chemically skinned vascular smooth muscle, phorbol ester induces a slowly developing contractile response at constant $\mathrm{Ca}^{2+}$ without any change in MLC phosphorylation. ${ }^{47}$ The production of a sustained response by PKC appears to involve phosphorylation of intermediate filaments (for example, desmin, synemin), caldesmon, and a small number of unidentified low molecular weight proteins. ${ }^{45}$ The role of PKC in HSC contraction has received little attention although its involvement is supported by the demonstration that inhibition of PKC prevents the response to ET- $1 .{ }^{48}$

\section{Phospholipase D (PLD)}

Evidence has recently emerged in support of the involvement of a further signalling pathway downstream of PKC. Stimulation of PKC results in activation of PLD and production of the second messenger phosphatidic acid (PA). ${ }^{49}$ Addition of exogenous PLD or PA to quiescent fibroblasts elicits the formation of actin stress fibres and PLD mediates PA induced stress fibre formation in these cells. ${ }^{50} 51$ Moreover, PLD colocalises with F-actin and three proteins, vinculin, talin, and $\alpha$-actinin, found on the cytoplasmic face of focal adhesions suggesting a role in the assembly/regulation of these structures. ${ }^{52}$

\section{"The data strongly suggest that investigations into the involvement of PKC/PLD in HSC contraction are likely to be fruifful areas of research for the future"}

Overexpression of PLD results in cytoskeletal reorganisation consistent with a regulatory role in contraction. ${ }^{53}$ Interestingly, PLD is regulated by both of the major pathways 


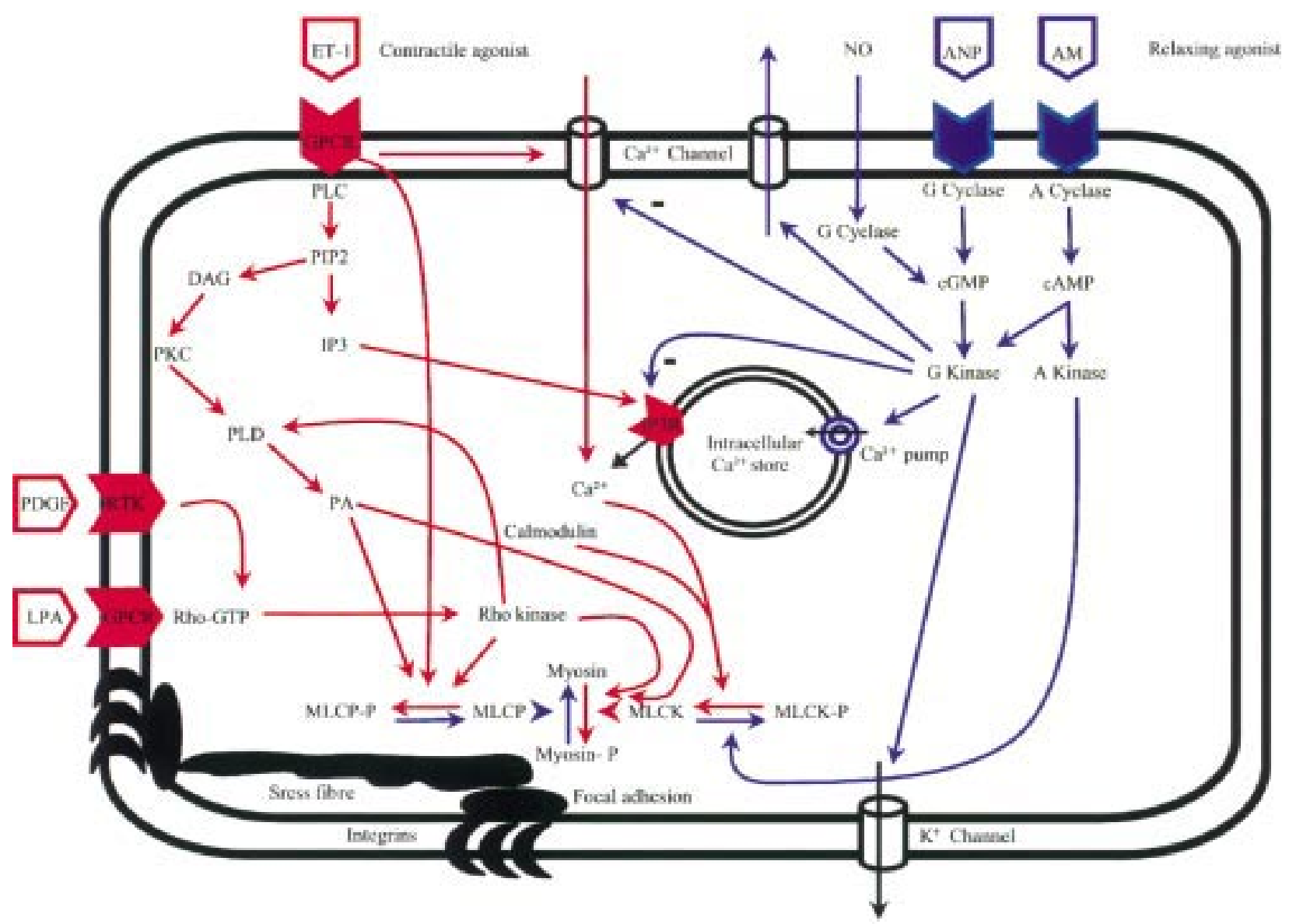

Figure 2 Schematic representation of intracellular contractile and relaxation mechanisms in hepatic stellate cells. It should be noted that most of the pathways have been described in smooth muscle cells but not all mechanism have been proved to exist in stellate cells. Pathways for contraction are marked in red whereas blue represents relaxation pathways. AM, adrenomedullin; ANP, atrial natriuretic peptide; DAG, diacylglycerol; ET-1, endothelin 1; GPCR, G protein coupled receptor; IP3, inositol 1,4,5-trisphosphate; LPA, lysophosphatidic acid; NO, nitric oxide; MLCK, myosin light chain kinase; MLCP, myosin light chain phosphatase; PIP2, phosphatidylinositol 4,5-bisphosphate; PLC, phospholipase C; PLD, phospholipase D; PKC, protein kinase C; RTK, receptor tyrosine kinase.

implicated in the control of contraction: a $\mathrm{Ca}^{2+}$ dependent kinase (that is, PKC) and rho (see below). Taken together, the data strongly suggest that investigations into the involvement of PKC/PLD in HSC contraction are likely to be fruitful areas of research for the future.

Phosphatidylinositol 3-kinase (PI(3)K)

To date, very few studies have investigated the possible involvement of PI(3) K in cell contraction. Evidence demonstrates that $\mathrm{PI}(3) \mathrm{K}$ is recruited to focal adhesions (see below) where it plays a structural/signalling role. The products of $\mathrm{PI}(3) \mathrm{K}$, phosphatidylinositol $(3,4)$ bisphosphate $(\mathrm{PI}(3,4) \mathrm{P} 2)$ and phosphatidylinositol $(3,4,5)$ trisphosphate $(\mathrm{PI}(3,4,5) \mathrm{P} 3)$ have been shown to mediate actin assembly in platelets. Their role, if any, in HSC contraction is presently unknown.

\section{Rho}

Rho is a member of the Ras superfamily and recent data demonstrate that activation of rho dependent responses is primarily mediated through $\mathrm{G}$ proteins of the Gol2/13 family. ${ }^{54} \mathrm{~A}$ number of rho effectors have been identified and the two serine/threonine kinases (rho kinase/ROK $\alpha /$ ROCK-II, and pl60ROCK/ROCK $\beta$ ), commonly referred to as rho kinase, are the best characterised. ${ }^{54}$ Rho regulates cell morphology through organising the actin cytoskeleton and control of actomyosin dependent cellular processes. ${ }^{55}$ Rho kinase has been shown to participate in the induction of stress fibre and focal adhesion formation and cell contraction. ${ }^{567}$ Furthermore, rho kinase also phosphorylates intermediate filaments, such as glial fibrillary acidic protein and vimentin..$^{58}$ In HSC, rho and rho kinase have been shown to enhance myosin activation suggesting a role in the generation of contractile force..$^{59}$ This possibility has been supported by the demonstration that rho signalling pathways regulate agonist (for example, ET-1, lysophosphatidic acid (LPA)) induced shrinkage of collagen gels. ${ }^{59}{ }^{60}$ Moreover, HSC activation was accompanied by rho induced formation of actin stress fibres and focal adhesions. ${ }^{61}$

Studies in smooth muscle have described an intriguing role for rho. Work with permeabilised blood vessels demonstrated that rho kinase mediated $\mathrm{Ca}^{2+}$ sensitisation and directly modulated smooth muscle contraction through MLC phosphorylation independently of the $\mathrm{Ca}^{2+}$-calmodulin MLC kinase pathway. ${ }^{62}$ Clearly, this is an area which requires further investigation in HSC.

\section{Recruitment of signalling proteins}

In fibroblasts, three of the agents shown to elicit HSC contraction (ET-1, vasopressin, and LPA) rapidly stimulate both (i) tyrosine phosphorylation of pl25 focal adhesion kinase (FAK) and paxillin and (ii) their clustering at focal adhesions, in a $\mathrm{Ca}^{2+}$ and PKC independent manner. ${ }^{63}{ }^{64}$ Evidence suggests that increased tyrosine phosphorylation is a consequence of activation of a tyrosine kinase situated upstream of rho and coupled to $\mathrm{G} \alpha 13 .{ }^{65}$ This results in the creation of binding sites for, and clustering of, other proteins-for example, src kinase and $\mathrm{PI}(3) \mathrm{K}$-at focal adhesions for structural/signalling 
functions. ${ }^{66}$ To date, protein phosphorylation (on tyrosine, serine, or threonine residues) in relation to contraction/ relaxation has received little attention in HSC.

\section{Myosin light chain}

As stated above, phosphorylation of MLC is a key pathway for actomyosin interaction. This is mediated by either $\mathrm{Ca}^{2+} /$ calmodulin dependent MLC kinase or rho kinase. The former directly phosphorylates MLC while the latter also acts through this mechanism and/or by regulating the activity of myosin phosphatase. ${ }^{67}{ }^{68}$ In HSC, phosphorylation of MLC by LPA correlates with its effects on contraction. Both responses are inhibited by the rho kinase inhibitor Y-27632, implying a link between rho kinase, MLC phosphorylation, and contraction. ${ }^{59}$

\section{Mechanisms of relaxation}

A survey of the literature shows that, in comparison with contraction, little is known of the signalling pathways which regulate HSC relaxation. In view of the proposed role of HSC contraction in portal hypertension, a detailed investigation into the mechanisms underlying HSC relaxation may ultimately have major clinical implications.

\section{Cyclic adenosine monophosphate (cAMP)}

An increase in cAMP appears to reduce HSC contraction. A cAMP dependent protein kinase has been reported to inactivate MLC kinase by phosphorylating two sites of the protein $^{69}$ and, moreover, the cell permeable cAMP analogue, dibutyryl cAMP, induces the disappearance of actin stress fibres in contracted HSC. ${ }^{48}$

\section{"An increase in cAMP appears to reduce HSC contraction"}

At high concentration, cAMP can activate a cGMP dependent kinase ( $\mathrm{G}$ kinase). Moreover, cAMP reduces $\mathrm{Ca}^{2+}$ influx, possibly by a direct effect on L type $\mathrm{Ca}^{2+}$ channels. ${ }^{70}$

\section{cGMP}

Elevation of NO, causing activation of guanylate cyclase, an increase in CGMP, and activation of G kinase appears to underlie the ability of sodium nitroprusside and interleukin 1 to promote HSC relaxation. ${ }^{25} 48$ In smooth muscle cells, G kinase has been shown to decrease $\left[\mathrm{Ca}^{2+}\right]_{\mathrm{i}}$ by several mechanisms: (i) decreasing $\mathrm{Ca}^{2+}$ influx by inhibiting L type $\mathrm{Ca}^{2+}$ channels, (ii) attenuation of IP3 induced $\mathrm{Ca}^{2+}$ release from intracellular stores, and (iii) increasing $\mathrm{Ca}^{2+}$ efflux by activation of $\mathrm{Ca}^{2+}$ ATPase. ${ }^{70}$ Moreover, sodium nitroprusside also induces disappearance of actin stress fibres in contracted HSC and nitric oxide has been reported to disrupt focal adhesion complexes. ${ }^{71}$

\section{MLC kinase and the formation of stress fibres/focal adhesions}

Stimulation of fibroblasts with LPA increases MLC phosphorylation with a time course preceding that for the detection of tyrosine phosphorylation, stress fibres, and focal adhesions. Moreover, pharmacological inhibition of MLC kinase prevented formation of stress fibres and focal adhesions, implying that MLC phosphorylation plays an important role in the formation/stability of these structures. ${ }^{72}$ Thus inhibition of MLC kinase by a cAMP/CGMP dependent kinase may underlie the disappearance of stress fibres/focal adhesions in activated HSC.

It is clear that the regulation of events described in this review results from cross talk between a number of signalling pathways. This is true not only for the equilibrium between contraction/relaxation but is also likely to be the case for what appear to be the two main signalling systems $\left(\mathrm{Ca}^{2+} / \mathrm{rho}\right)$ which control contraction. A detailed understanding of the interplay between these systems represents an important step towards the ultimate goal of designing novel treatments aimed at treating portal hypertension.

\section{VASOACTIVE SUBSTANCES INFLUENCING HSC CONTRACTILITY}

The effects of vasoactive substances have been extensively studied in activated stellate cells. One of the most potent and certainly the most studied vasoconstrictor is ET-1. Endothelins are a family of three homologous oligopeptides of 21 amino acid polypeptides (ET-1, ET-2, and ET-3) which are cleavage products of larger precursor proteins, cleaved by endothelin converting enzyme. ${ }^{73}$ The peptides act through at least two G protein coupled receptors, termed type $\mathrm{A}\left(\mathrm{ET}_{\mathrm{A}}\right)$ and type $\mathrm{B}$ $\left(\mathrm{ET}_{\mathrm{B}}\right)$, with $\mathrm{ET}_{\mathrm{B}}$ receptor having two isoforms: $\mathrm{ET}_{\mathrm{B} 1}$ and $\mathrm{ET}_{\mathrm{B} 2}{ }^{75}{ }^{76}$ The affinity of ET- 1 for the $\mathrm{ET}_{\mathrm{A}}$ receptor is 100 -fold higher than that of ET-3, whereas the $\mathrm{ET}_{\mathrm{B}}$ receptor has similar affinity for ET-1, ET-2, and ET-3. ${ }^{76}$ The $^{E_{\mathrm{A}}}$ receptor is mainly localised on smooth muscle cells and mediates principally vasoconstriction while $\mathrm{ET}_{\mathrm{B}}$ receptors are present on a variety of cells and have several biological effects. The $\mathrm{ET}_{\mathrm{B} 1}$ receptor induces endothelial cell nitric oxide synthetase (eNOS) resulting in $\mathrm{NO}$ release and relaxation whereas $\mathrm{ET}_{\mathrm{B} 2}$ receptors cause vasoconstriction. ${ }^{18} 7577$ Both $\mathrm{ET}_{\mathrm{A}}$ and $\mathrm{ET}_{\mathrm{B}}$ receptors were present on $\mathrm{HSC}$ and hepatocytes while only $\mathrm{ET}_{\mathrm{B}}$ receptors were present on sinusoidal endothelial cells and Kupffer cells. ${ }^{78-81}$

"In cirrhotic patients, a direct relationship between ET-1 mRNA receptor abundance and the degree of portal hypertension has been documented"

Compared with normal livers, the number of both ET receptors was increased in cirrhotic livers. ${ }^{82}$ In cirrhotic patients, a direct relationship between ET-1 mRNA receptor abundance and the degree of portal hypertension has been documented. ${ }^{83}$ Splanchnic ET-1 concentration was proportional to the degree of portal hypertension. ${ }^{84}$ In addition, increased plasma levels of ET- 1 in patients with cirrhosis have been documented by several investigators, and the grade of ET-1 elevation correlated with the severity of cirrhosis, presence of ascites, and presence of the hepatorenal syndrome ${ }^{84-95}$ Very high levels of ET- 1 have been measured in the splanchnic vessels but the highest levels of ET- 1 have been found in hepatic veins. ${ }^{849095}$ In patients with portal hypertension, at least part of ET-l is produced in the gut and spleen. ${ }^{95}$ Moreover, it has been shown that ET-1 synthesis occurred within the liver. Indeed, cultured sinusoidal endothelial cells and hepatocytes have been shown to release ET- $1 .{ }^{81}{ }^{96}$ Both ET-1 mRNA and protein were markedly elevated in cirrhotic liver tissue. Activated HSC have been shown to be a major site of ET-1 synthesis via differential regulation of endothelin converting enzyme 1 mRNA and protein. ${ }^{97-99}$ Furthermore, during activation of HSC, sensitivity to ET- 1 was increased. ${ }^{27} 28$ Enhanced ET- 1 synthesis and release, and increased sensitivity to ET-1, suggest the possibility of a paracrine or autocrine action of ET- $1 .{ }^{98}$

"Short term blockade of ET receptors by mixed $\mathrm{ET}_{A} / \mathrm{ET}_{\mathrm{B}}$
receptor antagonists decreased portal hypertension in
some models of experimental cirrhosis"

In the early phase of activation of $\mathrm{HSC}, \mathrm{ET}_{\mathrm{A}}$ receptors were predominant but with increasing activation $\mathrm{ET}_{\mathrm{B}}$ receptors became increasingly more abundant. ${ }^{97}$ This shift in receptor densities might be important in view of the different effects of ET- 1 during the process of activation of HSC. Stimulation of $\mathrm{ET}_{\mathrm{A}}$ receptors caused contraction and proliferation of HSC whereas $\mathrm{ET}_{\mathrm{B}}$ receptor stimulation resulted in antiproliferative effects and relaxation..$^{97100}{ }^{101}$ In cultured HSC, ET- 1 induced a 
dose dependent increase in $\left[\mathrm{Ca}^{2+}\right]_{\mathrm{i}}$ both by release of $\mathrm{Ca}^{2+}$ from intracellular stores and by stimulating $\mathrm{Ca}^{2+}$ influx coupled with contraction of the cells. ${ }^{5}$ ET-1 was shown to elicit sustained vasoconstriction of the hepatic vasculature. ${ }^{102}$ Short term blockade of $\mathrm{ET}$ receptors by mixed $\mathrm{ET}_{\mathrm{A}} / \mathrm{ET}_{\mathrm{B}}$ receptor antagonists decreased portal hypertension in some models of experimental cirrhosis..$^{29}{ }^{103-105}$ However, these results could not be confirmed following chronic blockade of ET receptors. ${ }^{106}$ Indeed, in cirrhotic rats treated with an ET receptor antagonist no differences in portal pressure were found but higher hepatic hydroxyproline content and procollagen type I mRNA expression were demonstrated.

NO is an omnipresent messenger molecule involved in various cellular processes, including neurotransmission, inflammation, and regulation of vascular tone. It is a potent vasodilator, acting in a paracrine fashion by directly stimulating soluble guanylate cyclase, resulting in increased levels of cGMP and consequently decreased $\left[\mathrm{Ca}^{2+}\right]_{\mathrm{i}}$ and vasorelaxation. Although NO has a short half life, it has prolonged effects by metabolites such as peroxynitrate. Nitric oxide is produced from L-arginine by three isoforms of nitric oxide synthetase (NOS). A wide variety of cells, including vascular smooth muscle cells, hepatocytes, and HSC, express the inducible form of NOS (iNOS) whereas endothelial cells (eNOS) and neuronal cells (nNOS) express constitutive NOS forms. ${ }^{107} 108$ Several growth factors (for example, transforming growth factor $\beta$, vascular endothelial growth factor), hypoxia, and shear stress increase eNOS mRNA while tumour necrosis factor $\alpha$ decreases its expression. The constitutive isoforms respond to changes in $\left[\mathrm{Ca}^{2+}\right]_{\mathrm{i}}$ and produce small amounts of NO. The iNOS isoform is modulated by a variety of stimuli, including cytokines and lipopolysaccharide. The enzyme binds calmodulin at almost all $\left[\mathrm{Ca}^{2+}\right]_{\mathrm{i}}$ concentrations and NO production is high. ${ }^{107}{ }^{109}$ In cirrhosis, systemic and splanchnic vascular NO production is increased resulting in the development of a hyperdynamic syndrome. It appears that eNOS is responsible for the enhanced NO synthesis but the cause is not entirely clear. ${ }^{108}$ In contrast with the high NO production in the systemic and splanchnic vascular system, NO production within the cirrhotic liver is deficient. It has been demonstrated that NO modulates hepatic vascular tone in normal liver, and that sinusoidal endothelial cells express both in vitro and in vivo eNOS and produce NO. ${ }^{11011}$ Not only are sinusoidal endothelial cells responsible for basal NO production but also for increased release of $\mathrm{NO}$ in response to flow and shear stress. ${ }^{111}$ Exogenous NO abolished the vasoconstricive effects of ET- 1 in the in vitro perfused rat liver. ${ }^{1412}$ In the cirrhotic liver however, endothelial dysfunction with decreased NO synthesis by sinusoidal endothelial cells caused by decreased enzymatic function of eNOS has been reported. ${ }^{13-115} \mathrm{NO}$ was shown to modulate the contractile effect of ET- 1 on cultured HSC. ${ }^{48} 116$ Interleukin $1 \beta$, tumour necrosis factor $\alpha$, or lipopolysaccharides in combination with interferon $\gamma$ led to increased iNOS mRNA levels in HSC and increased nitrite levels, possibly by an autocrine mechanism. ${ }^{116}$ However, iNOS mRNA and nitrite were not found in HSC cultured from $\mathrm{CCl}_{4}$ treated rat livers. ${ }^{117}$ Apart from vasoactive effects, deficient NO in cirrhosis has some other effects: (i) increased thrombogenesis, (ii) enhanced synthesis and deposition of collagen in the space of Disse, (iii) decreased suppression of specific adhesion molecules, and (iv) decreased protection against free oxygen radicals. ${ }^{108}$

Although endothelins and NO are probably the most important and certainly the most studied vasoactive substances, several other substances have been investigated. In denervated, isolated, perfused rat liver, atrial natriuretic peptide (ANP) antagonised the increased intrahepatic vascular resistance elicited by phenylephrine. ${ }^{118}$ Cultured human HSC have receptors for ANP and activation of these receptors reduced the effects of ET- 1 on $\left[\mathrm{Ca}^{2+}\right]_{\mathrm{i}}$ and cell contraction. ${ }^{411}{ }^{419}$ The relaxing effects were shown to be mediated by $\mathrm{C}$ type ANP inducing an increase in cGMP and by blockade of store operated calcium channels. ${ }^{41}$ Adrenomedullin is a potent vasodilator of which circulating plasma levels have been shown to be elevated in cirrhosis, as a function of haemodynamic changes. ${ }^{120}{ }^{121}$ It has been demonstrated that human HSC have functional receptors for adrenomedullin, stimulation of which blunted the contractile effect of ET- $1 .{ }^{122}$ Adrenomedullin exerts its relaxing effects in HSC through cAMP cascades. ${ }^{123}$ Interestingly, both cytokines and shear stress augmented expression of C type ANP and adrenomodullin. ${ }^{124}$ Somatostatin is used to treat acute variceal bleeding. Somatostatin inhibits the secretion of glucagon, a well known vasodilating agent. Moreover, in the presence of vasoconstrictors involving activation of PKC, octreotide had a vasoconstrictive effect on vascular smooth muscle of the superior mesenteric artery. ${ }^{125}$ We have shown that, in addition to the effects on portal blood flow, activation of the somatostatin receptor subtype 1 caused partial inhibition of ET- 1 induced contraction of stellate cells. ${ }^{126}$

Several other substances have been investigated in vitro but the in vivo significance on portal pressure remains unclear. Vascular endothelial growth factor inhibited contraction of cultured HSC by attenuating $\alpha$ smooth muscle actin expression. ${ }^{127}$ Agents increasing intracellular cAMP (for example, adrenomedullin, Iloprost, prostaglandin $\mathrm{E}_{2}$ ) and cGMP (for example, lipopolysaccharide, interferon $\gamma$, interleukin $\beta$, ANP, NO) induce relaxation of stellate cells. $^{25} 4148122128129$

"Although different effects on portal pressure have been claimed, to date no definite role in portal hypertension has been attributed to most eicosanoids"

Some prostaglandins (for example, $\mathrm{PGI}_{2}, \mathrm{PGE}_{2}$ ) induced relaxation of cultured HSC whereas others (for example, thromboxane, $\mathrm{PGF}_{2 \alpha}$ ) induced contraction. ${ }^{128}$ Although different effects on portal pressure have been claimed, to date no definite role in portal hypertension has been attributed to most eicosanoids. Administration of leukotriene $\mathrm{D}_{4}$, a 5-lipoxygenase derived eicosanoid, resulted in marked HSC contraction coupled with increased $\left[\mathrm{Ca}^{2+}\right]_{1}$. Moreover, leukotriene $\mathrm{D}_{4}$ administration significantly increased portal pressure in rats. ${ }^{130}$

Antidiuretic hormone or vasopressin, a potent vasoconstrictor acting through $\mathrm{V}_{1}$ receptors on vascular smooth muscle cells, was successfully used to treat acute variceal bleeding. Vasopressin also elicited contraction of cultured human HSC through $V_{1}$ receptors. Stimulation of $V_{1}$ receptors is coupled with increased $\left[\mathrm{Ca}^{2+}\right]_{\mathrm{i}}$ caused by release of $\mathrm{Ca}^{2+}$ from intracellular stores. ${ }^{131}$ Similar to vasopressin, thrombin induced dose dependent contraction of activated human HSC. ${ }^{51}$ Thrombin induced contraction is coupled with a rise in $\left[\mathrm{Ca}^{2+}\right]_{\mathrm{i}}$ via release of $\mathrm{Ca}^{2+}$ from intracellular stores and via store operated ${ }^{41}$ or voltage operated Ca channels. ${ }^{5}$ It has been known for many years that the renin-angiotensin system plays a role in increased intrahepatic vascular resistance and that the activity of the renin-angiotensin system correlates with the degree of portal hypertension. ${ }^{132}$ Angiotensin II (ANGII) is an octapeptide primarily acting through type 1 angiotensin receptor (AT1). ${ }^{133}$ Infusion of ANGII resulted in increased intrahepatic vascular resistance and portal hypertension in experimental cirrhosis. In activated, but not in quiescent, human HSC, ANGII induced an ATl mediated dose dependent increase in $\left[\mathrm{Ca}^{2+}\right]_{\mathrm{i}}$ accompanied by proliferation and cell contraction. ${ }^{5}{ }^{134}$ In rat HSC however, ANGII did not induce contraction of collagen lattices ${ }^{28}$ Either rat HSC do not bear ATl or the method used to measure contraction was not sufficiently sensitive. Substance P caused a dose dependent contraction of rat HSC cultured for 24 hours. ${ }^{26}$ Substance P was increased in decompensated cirrhotic rats and patients, although no direct relation with portal pressure was 
found. ${ }^{135}{ }^{136}$ Stellate cells have nucleotide receptors which are triggered by adenosine, resulting in receptor mediated contraction of the cells. ${ }^{137}$ LPA, a product of phospholipid metabolism released by activated platelets, was shown to induce HSC contraction by a mechanism involving rho kinase. ${ }^{59}$

Although activated HSC contract in response to vasoactive substances, both in vivo and in vitro, there has been some debate as to whether stellate cell contraction is forceful enough to produce sinusoidal constriction. This issue was resolved in a recent study in which stellate cell contraction was directly quantitated. ${ }^{138}$ It was demonstrated that the average force generated by ET- 1 induced contraction of a single HSC was $\sim 0.69$ dyn or $14000 \mathrm{dyn} / \mathrm{cm}^{2}$, which is greater than the sinusoidal pressure in cirrhotic rats, indicating that HSC can constrict sinusoids and thus contribute to increased sinusoidal resistance.

\section{PHARMACOLOGICAL TREATMENT OPTIONS DIRECTED TOWARDS HSC}

Fibrosis remains the principal cause of increased vascular resistance in liver disease. Because HSC play a key role in the development of liver fibrosis, much effort has been made in the development of drugs acting on HSC in order to prevent or revert the process of fibrosis. Potential therapies are currently under investigation. ${ }^{139}$

\section{"Most drugs are directed towards lowering portal blood flow but new drugs acting on HSC contractility are being investigated"}

Although clinical experimental studies indicate that hepatic fibrosis is partially reversible, complete resolution of cirrhosis with re-establishment of normal liver histology will probably not be possible. Hence portal hypertension and its complications will continue to be a major challenge for clinicians. Therefore, effective antiportal hypertensive drugs are needed. Currently, most drugs are directed towards lowering portal blood flow but new drugs acting on HSC contractility are being investigated. Ideally, a drug should be antifibrotic, induce stellate cell relaxation, and decrease portal blood flow. Some potential candidates will be discussed briefly.

In view of the beneficial effects of endothelin via activation of $\mathrm{ET}_{\mathrm{B}}$ receptors and the negative effects of $\mathrm{ET}_{\mathrm{A}}$ receptor stimulation (contraction and proliferation of HSC), selective blockade of $\mathrm{ET}_{\mathrm{A}}$ receptors would be a good approach to treating portal hypertension. Oral administration of a selective $\mathrm{ET}_{\mathrm{A}}$ receptor antagonist ameliorated portal hypertension in portal vein ligated rats ${ }^{140}$ and reduced fibrosis in a bile duct ligation model. ${ }^{141}$ So far no solid clinical data are available in cirrhotic patients. Although $\mathrm{ET}_{\mathrm{B}}$ receptor agonists and endothelin converting enzyme inhibitors are theoretically very interesting molecules, up to now no in vivo data are available.

Apart from the relaxing effects of NO on HSC, antiproliferative effects of NO have been demonstrated in vitro. ${ }^{142}$ Although NO causes relaxation of HSC, it also increases splanchnic blood flow, and systemic non-specific NO donors will probably not be clinically useful in treating portal hypertension. Because of local intrahepatic NO deficiency, another approach has been explored. Transduction of livers with recombinant adenoviruses carrying the nNOS gene significantly reduced intrahepatic resistance and portal pressure in two different in vivo models of cirrhosis and portal hypertension. ${ }^{143}$

Losartan, a specific ATl receptor antagonist, completely blocked the effects of ANGII on HSC contraction and proliferation and induced a significant decrease in portal hypertension in cirrhotic patients. ${ }^{134}{ }^{144}$ Long term effects and side effects have to be examined.

However, long term losartan administration did not significantly reduce hepatic vein pressure gradient in cirrhotic patients. Moreover, it caused hypotension and reduced glomerular filtration rate in these patients. Therefore, losartan does not seem to be a good treatment option. ${ }^{145}$

Inhibition of rho signalling by a specific inhibitor of rho kinase (Y-27632) decreased HSC contraction, proliferation, migration, and activation associated morphological alterations. ${ }^{60}{ }^{61} 146147$ It also reduced ET- 1 induced portal vein constriction in an ex vivo liver perfusion model but no in vivo experiments have been published so far. ${ }^{60}$

Somatostatin is a well established drug to treat acute variceal haemorrhage. Apart from vasoconstrictive effects on mesenteric arteries ${ }^{125}$ and relaxing effect on rat stellate cells, ${ }^{126}$ antifibrotic effects have been attributed to somatostatin analogues in in vivo animal models. ${ }^{148}$ We have demonstrated decreased production of collagen I and III by cultured HSC in the presence of somatostatin, suggesting that somatostatin also has a direct antifibrotic effect. ${ }^{149}$

\section{CONCLUSION}

Hepatic stellate cells are key players in the pathogenesis of fibrosis and portal hypertension. Hence HSC have become therapeutic targets to treat these complications of chronic liver disease. HSC probably also play a role in the normal liver microcirculation. The contractile apparatus of HSC and the signalling pathways that control contraction or relaxation require further in depth studies. Antifibrotic and vasomotor effects of multiple agents have been exhaustively investigated, predominantly in vitro and in experimental animal models. These studies have led to the identification of drugs causing inhibition of activation and relaxation of HSC, thereby decreasing fibrosis and portal pressure. Based on this experimental work, clinical studies in patients will have to be undertaken.

\section{Authors' affiliations}

H Reynaert, Laboratory for Molecular Liver Cell Biology, Free University Brussels (VUB), Brussels, Belgium

M G Thompson, T Thomas, Department of Medical Cell Biology and Centre for Liver Research, University of Newcastle-upon-Tyne, UK A Geerts, Laboratory for Molecular Liver Cell Biology, Free University Brussels (VUB), Brussels, Belgium and Department of Medical Cell Biology and Centre for Liver Research, University of Newcastle-upon-Tyne, UK

\section{REFERENCES}

1 Gupta TK, Chen L, Groszmann RJ. Pathophysiology of portal hypertension. Baillieres Clin Gastroenterol 1997;11:203-19.

2 Bhathal PS, Grossmann HJ. Reduction of the increased portal vascular resistance of the isolated perfused rat liver by vasodilators. J Hepatol 1985; 1:325-37.

3 Reichen J, Le M. Verapamil favorably influences hepatic microvascular exchange and function in rats with cirrhosis of the liver. J Clin Invest 1986;78:448-55.

4 Ramadori G. The stellate cell of the liver. Virchows Arch B Cell Pathol $1991 ; 61: 147-58$

5 Pinzani M, Failli P, Ruocco C, et al. Fat-storing cells as liver-specific pericytes. Spatial dynamics of agonist-stimulated intracellular calcium transients. J Clin Invest 1992;90:642-6.

6 Pinzani M. Hepatic stellate (ITO) cells: expanding roles for a liver-specific pericyte. J Hepatol 1995;22:700-6.

7 Friedman SL. Molecular regulation of hepatic fibrosis, an integrated cellular response to tissue injury. J Biol Chem 2000;275:2247-50.

8 Burt AD, Le Bail B, Balabaud C, et al. Morphologic investigation of sinusoidal cells. Semin Liver Dis 1993;13:21-38.

9 Stoyanova II, Gulubova MV. Immunocytochemical study on the liver innervation in patients with cirrhosis. Acta Histochem 2000;102:391402.

10 Geerts A. History, heterogeneity, developmental biology and functions of quiescent hepatic stellate cells. Semin Liver Dis 2001;21:311-35.

11 McCuskey RS. Morphological mechanisms for regulating blood flow through hepatic sinusoids. Liver 2000;20:3-7

12 Bhunchet E, Wake K. The portal lobule in rat liver fibrosis: a re-evaluation of the liver unit. Hepatology 1998;27:481-7.

13 Nakata K, Leong GF, Braver RW. Direct measurements of blood pressures in minute vessels of the liver. Am J Physiol 1960;199:1181-8.

14 Zhang JX, Pegoli WJ, Clemens MG. Endothelin-1 induces direct constriction of hepatic sinusoids. Am J Physiol 1994;266:G624-32.

15 Zhang JX, Baver M, Clemens MG. Vessel- and target cell-specific actions of endothelin-1 and endothelin- 3 in rat liver. Am J Physiol 1995;269:G269-77. 
16 Okumura S, Takei $Y$, Kawano $S$, et al. Vasoactive effect of endothelin-1 on rat liver in vivo. Hepatology 1994;19:155-61.

17 Baver M, Zhang JX, Baver I, et al. ET-1 induced alterations of hepatic microcirculation: sinusoidal and extrasinusoidal sites of action. Am J Physiol 1994;267: G143-9.

18 Baver M, Baver I, Zhang JX, et al. Functional significance of endothelin $B$ receptors in mediating sinusoidal and extrasinusoidal effects of endothelins in the intact rat liver. Hepatology 2000;31:937-47.

19 Clemens MG, Zhang JX. Regulation of sinusoidal perfusion: In vivo methodology and control by endothelins. Semin Liver Dis 1999:19:383-96.

20 Suematsu $M$, Ishimura $Y$. The heme oxygenase-carbon monoxide system: A regulator of hepatobiliary function. Hepatology 2000;31:3-6

21 Goda N, Suzuki K, Naito M, et al. Distribution of heme oxygenase isoforms in rat liver. Topographic basis for carbon monoxide-mediated microvascular relaxation. J Clin Invest 1998;101:604-12.

22 Suematsu M, Goda N, Sano T, et al. Carbon monoxide: an endogenous modulator of sinusoidal tone in the perfused rat liver. J Clin Invest 1995;96:2431-7.

23 Kaneda K, Ekataksin W, Sogawa M, et al. Endothelin-1-induced vasoconstriction causes a significant increase in portal pressure of rat liver: localized constrictive effect on distal segment of preterminal portal venules as revealed by light and electron microscopy and serial reconstruction. Hepatology 1998;27:735-47.

24 McCuskey RS, Ito Y, McCuskey M, et al. Morphological mechanisms for regulating blood flow through hepatic sinusoids. In: Wisse $\mathrm{E}, \mathrm{Knook} \mathrm{DL}$ Fraser R, eds. Cells of the hepatic sinusoid, 7th edn. Leiden: Kupffer Cell Foundation, 1999 (1998 update and review): 129-34

25 Sakamoto $M$, Ueno T, Sugawara $H$, et al. Relaxing effect of interleukin-1 on rat cultured lto cells. Hepatology 1997;25:1412-17.

26 Sakamoto $M$, Ueno $T$, Kin $M$, et al. Ito cell contraction in response to endothelin-1 and substance P. Hepatology 1993;18:978-83.

27 Reinehr RM, Kubitz R, Peters-Regehr T, et al. Activation of rat hepatic stellate cells in culture is associated with increased sensitivity to endothelin 1. Hepatology 1998;28:1566-77.

28 Rockey DC, Housset CN, Friedman SL. Activation-dependent contractility of rat hepatic lipocytes in culture and in vivo. J Clin Invest 1993;92:1795-804

29 Rockey DC, Weisiger RA. Endothelin induced contractility of stellate cells from normal and cirrhotic rat liver: implications for regulation of portal pressure and resistance. Hepatology 1996;24:233-40.

30 Ekataksin W, Kaneda K. Liver microvascular architecture: an insight into the pathophysiology of portal hypertension. Semin Liver Dis 1999; 19:359-82.

31 Lehman W, Craig R, Vibert P. Ca(2+)-induced tropomyosin movement in Limulus thin filaments revealed by three-dimensional reconstruction. Nature 1994;368:65-7.

32 Haeberle JR. Thin-filament linked regulation of smooth muscle myosin. J Muscle Res Cell Motil 1999; 20:363-70.

33 Gerthoffer WT, Pohl J. Caldesmon and calponin phosphorylation in regulation of smooth muscle contraction. Can J Physiol Pharmacol 1994:72:1410-14.

34 Kashiwada K, Nishida W, Hayashi K, et al. Coordinate expression of alpha-tropomyosin and caldesmon isoforms in association with phenotypic modulation of smooth muscle cells. J Biol Chem 1997; 272: 15396-404.

35 Danninger C, Gimona M. Live dynamics of GFP-calponin: isoform-specific modulation of the actin cytoskeleton and autoregulation by C-terminal sequences. J Cell Sci 2000;113(Pt 21):3725-36.

36 Jin JP, Walsh MP, Sutherland C, et al. A role for serine-175 in modulating the molecular conformation of calponin. Biochem $J$ 2000;350(Pt 2):579-88.

37 Somlyo AP, Somlyo AV. Signal transduction by G-proteins, rho-kinase and protein phosphatase to smooth muscle and non-muscle myosin II. Physiol 2000;522(Pt 2): 177-85.

38 Yee HFJ, Melton AC, Tran BN. RhoA/rho-associated kinase mediates fibroblast contractile force generation. Biochem Biophys Res Commun 2001;280:1340-5

39 Yee HFJ. $\mathrm{Ca}^{2+}$ and rho signaling pathways: two paths to hepatic stellate cell contraction. Hepatology 2001;33:1007-8.

40 Berridge MJ. Inositol trisphosphate and diacylglycerol: two interacting second messengers. Annu Rev Biochem 1987;56:159-93.

41 Tao J, Mallat A, Gallois C, et al. Biological effects of C-type natriuretic peptide in human myofibroblastic stellate cells. J Biol Chem 1999:274:23761-9.

42 Bataller R, Gasull X, Gines P, et al. In vitro and in vivo activation of rat hepatic stellate cells results in de novo expression of L-type voltage-operated calcium channels. Hepatology 2001;33:956-62.

43 Somlyo AP, Somlyo AV. Signal transduction and regulation in smooth muscle. Nature 1994;372:231-6.

44 Bataller R, Nicolas JM, Ginees P, et al. Contraction of human hepatic stellate cells activated in culture: a role for voltage-operated calcium channels. J Hepatol 1998;29:398-408.

45 Rasmussen H, Takuwa Y, Park S. Protein kinase $C$ in the regulation of smooth muscle contraction. FASEB J 1987;1:177-85.

46 Forder J, Scriabine A, Rasmussen H. Plasma membrane calcium flux protein kinase $\mathrm{C}$ activation and smooth muscle contraction. J Pharmacol Exp Ther 1985;235:267-73.

47 Chatteriee $M$, Tejada $M$. Phorbol ester-induced contraction in chemically skinned vascular smooth muscle. Am J Physiol 1986;251:C356-61.

48 Kawada N, Tran-Thi TA, Klein H, et al. The contraction of hepatic stellate (lto) cells stimulated with vasoactive substances. Possible involvement of endothelin 1 and nitric oxide in the regulation of the sinusoidal tonus. Eur J Biochem 1993:213:815-23.

49 Liscovitch M, Czarny M, Fiucci G, et al. Phospholipase D: molecular and cell biology of a novel gene family. Biochem J 2000;345(Pt 3):401-15.

50 Cross MJ, Roberts S, Ridley AJ, et al. Stimulation of actin stress fibre formation mediated by activation of phospholipase D. Curr Biol 1996:6:588-97.

51 Ha KS, Exton JH. Activation of actin polymerization by phosphatidic acid derived from phosphatidylcholine in IIC9 fibroblasts. J Cell Biol 1993; 123: 1789-96

52 Iyer SS, Kusner DJ. Association of phospholipase D activity with the detergent-insoluble cytoskeleton of U937 promonocytic leukocytes. J Biol Chem 1999;274:2350-9.

53 Colley WC, Sung TC, Roll R, et al. Phospholipase D2, a distinct phospholipase $\mathrm{D}$ isoform with novel regulatory properties that provokes cytoskeletal reorganization. Curr Biol 1997;7:191-201.

54 Sah VP, Seasholtz TM, Sagi SA, et al. The role of Rho in G protein-coupled receptor signal transduction. Annu Rev Pharmacol Toxicol 2000;40:459-89.

55 Ridley AJ, Hall A. The small GTP-binding protein rho regulates the assembly of focal adhesions and actin stress fibers in response to growth factors. Cell 1992;70:389-99.

56 Amano M, Chihara K, Kimura K, et al. Formation of actin stress fibers and focal adhesions enhanced by Rho-kinase. Science 1997;275:1308-11

57 Uehata $M$, Ishizaki $T$, Satoh $H$, et al. Calcium sensitization of smooth muscle mediated by a Rho-associated protein kinase in hypertension. Nature 1997;389:990-4

58 Amano M, Fukata Y, Kaibuchi K. Regulation and functions of Rho-associated kinase. Exp Cell Res 2000;261:44-51

59 Yanase $M$, Ikeda H, Matsui A, et al. Lysophosphatidic acid enhances collagen gel contraction by hepatic stellate cells: association with rho-kinase. Biochem Biophys Res Commun 2000;277:72-8.

60 Kawada N, Seki S, Kuroki T, et al. ROCK inhibitor Y-27632 attenuates stellate cell contraction and portal pressure increase induced by endothelin-1. Biochem Biophys Res Commun 1999;266:296-300.

61 Yee HFJ. Rho directs activation-associated changes in rat hepatic stellate cell morphology via regulation of the actin cytoskeleton. Hepatology 1998;28:843-50.

62 Kureishi Y, Kobayashi S, Amano M, et al. Rho-associated kinase directly induces smooth muscle contraction through myosin light chain phosphorylation. J Biol Chem 1997;272:12257-60.

63 Zachary I, Sinnett-Smith J, Turner CE, et al. Bombesin, vasopressin, and endothelin rapidly stimulate tyrosine phosphorylation of the focal adhesion-associated protein paxillin in Swiss 3T3 cells. J Biol Chem 1993;268:22060-5.

64 Sinnett-Smith J, Zachary I, Valverde AM, et al. Bombesin stimulation of p1 25 focal adhesion kinase tyrosine phosphorylation. Role of protein kinase $\mathrm{C}, \mathrm{Ca}^{2+}$ mobilization, and the actin cytoskeleton. J Biol Chem 1993;268:14261-8

65 Gohla A, Offermanns S, Wilkie TM, et al. Differential involvement of Galpha 12 and Galpha13 in receptor-mediated stress fiber formation. J Biol Chem 1999:274:17901-7.

66 Chen HC, Appeddu PA, Isoda H, et al. Phosphorylation of tyrosine 397 in focal adhesion kinase is required for binding phosphatidylinosito 3-kinase. J Biol Chem 1996;271:26329-34

67 Amano $M$, Ito $M$, Kimura $K$, et al. Phosphorylation and activation of myosin by Rho-associated kinase (Rho-kinase). J Biol Chem 1996:271:20246-9.

68 Kimura K, Ito $M$, Amano $M$, et al. Regulation of myosin phosphatase by Rho and Rho-associated kinase (Rho-kinase). Science 1996;273:245-8.

69 Adelstein RS, Conti MA, Hathaway DR, et al. Phosphorylation of smooth muscle myosin light chain kinase by the catalytic subunit of adenosine 3' 5'-monophosphate-dependent protein kinase. J Biol Chem 1978;253:8347-50.

70 Rembold CM. Bárány $M$, eds. Biochemistry of smooth muscle contraction. San Diego: Academic Press, 1996:227-39.

71 Clancy RM, Rediske J, Tang X, et al. Outside-in signaling in the chondrocyte. Nitric oxide disrupts fibronectin-induced assembly of a subplasmalemmal actin/rho A/focal adhesion kinase signaling complex. J Clin Invest 1997; 100:1789-96.

72 Chrzanowska-Wodnicka M, Burridge K. Rho-stimulated contractility drives the formation of stress fibers and focal adhesions. J Cell Biol 1996; 133:1403-15.

73 Inoue $M$, Yanagiasawa M, Kimura S, et al. The human endothelin family: three structurally and pharmacologically distinct isopeptides predicted by three separate genes. Proc Natl Acad Sci USA 1989;86:2863-7.

74 Xu D, Emoto N, Giaid A, et al. ECE-1: a membrane-bound metalloprotease that catalyzes the proteolytic activation of big endothelin-1. Cell 1994;78:473-85

75 Clozel M, Gray GA, Breu V, et al. The endothelin ETB receptor mediates both vasodilation and vasoconstriction in vivo. Biochem Biophys Res Commun 1992;186:867-73.

76 Sakurai T, Yanagiasawa M, Masaki T. Molecular characterization of endothelin receptors. Trends Pharmacol Sci 1992;13:103-8.

77 Higuchi $\mathbf{H}$, Satoh T. Endothelin-1 induces vasoconstriction and nitric oxide release via endothelin ET(B) receptors in isolated perfused rat liver. Eur J Pharmacol 1997;328:175-82.

78 Housset C, Rockey DC, Bissell DM. Endothelin receptors in rat liver: lipocytes as a contractile target for endothelin 1. Proc Natl Acad Sci USA 1993:90:9266-70 
79 Jouneaux C, Mallat A, Serradeil-Le GC, et al. Coupling of endothelin B receptors to the calcium pump and phospholipase $C$ via $\mathrm{Gs}$ and $\mathrm{Gq}$ in rat liver. J Biol Chem 1994;269:1845-51

80 Serradeil-Le GC, Jouneaux C, Sanchez-Bueno A, et al. Endothelin action in rat liver. Receptors, free $\mathrm{Ca}^{2+}$ oscillations, and activation of glycogenolysis. J Clin Invest 1991:87:133-8.

81 Kuddus RH, Nalesnik MA, Subbotin VM, et al. Enhanced synthesis and reduced metabolism of endothelin-1 (ET-1) by hepatocytes - an importan mechanism of increased endogenous levels of ET-1 in liver cirrhosis. $J$ Hepatol 2000;33:725-32

82 Yokomori H, Oda M, Ogi $M$, et al. Enhanced expression of endothelin receptor subtypes in cirrhotic rat liver. Liver 2001;21:114-22.

83 Leivas A, Jimenez W, Bruix J, et al. Gene expression of endothelin-1 and $E T(A)$ and $E T(B)$ receptors in human cirrhosis: relationship with hepatic hemodynamics. J Vasc Res 1998;35:186-93.

84 Gerbes AL, Moller S, Gulberg V, et al. Endothelin-1 and -3 plasma concentrations in patients with cirrhosis: role of splanchnic and renal passage and liver function. Hepatology 1995;21:735-9

85 Moore K, Wendon J, Frazer M, et al. Plasma endothelin immunoreactivity in liver disease and the hepatorenal syndrome. N Engl J Med 1992;327:1774-8.

86 Uchihara M, Izumi N, Sato C, et al. Clinical significance of elevated plasma endothelin concentration in patients with cirrhosis. Hepatology 1992; 16:95-9.

87 Asbert M, Gines A, Gines P, et al. Circulating levels of endothelin in cirrhosis. Gastroenterology 1993:104:1485-91.

88 Moller S, Emmeluth C, Henriksen JH. Elevated circulating plasma endothelin-1 concentrations in cirrhosis. J Hepatol 1993; 19:285-90.

89 Matsumoto $\mathbf{H}$, Uemasu J, Kitano $M$, et al. Clinical significance of plasma endothelin-1 in patients with chronic liver disease. Dig Dis Sci 1994;39:2665-70.

90 Moller S, Gulberg V, Henriksen JH, et al. Endothelin-1 and endothelin-3 in cirrhosis: relations to systemic and splanchnic haemodynamics. J Hepatol 1995; 23:135-44.

91 Salo J, Francitorra A, Follo A, et al. Increased plasma endothelin in cirrhosis. Relationship with systemic endotoxemia and response to changes in effective blood volume. J Hepatol 1995;22:389-98.

92 Tsai YT, Lin HC, Yang MC, et al. Plasma endothelin levels in patients with cirrhosis and their relationships to the severity of cirrhosis and renal function. J Hepatol 1995;23:681-8.

93 Martinet JP, Legault L, Cernacek $\mathrm{P}$, et al. Changes in plasma endothelin-1 and Big endothelin-1 induced by transjugular intrahepatic portosystemic shunts in patients with cirrhosis and refractory ascites. J Hepatol 1996;25:700-6

94 Bernardi M, Gulberg V, Colantoni A, et al. Plasma endothelin-1 and -3 in cirrhosis: relationship with systemic hemodynamics, renal function and neurohumoral systems. J Hepatol 1996;24:161-8.

95 Nagasue N, Dhar DK, Yamanoi YE, et al. Production and release of endothelin-1 from the gut and spleen in portal hypertension due to cirrhosis. Hepatology 2000;31:1107-14

96 Rieder H, Ramadori G, Meyer zum Buschenfelde KH. Sinusoidal endothelial liver cells in vitro release endothelin: augmentation by transforming growth factor $\beta$ and Kupffer cell-conditioned media. Klin Wochenschr 1991;69:387-91.

97 Pinzani M, Milani S, De Franco R, et al. Endothelin 1 is overexpressed in human cirrhotic liver and exerts multiple effects on activated hepatic stellate cells. Gastroenterology 1996;1 10:534-48.

98 Rockey D, Fouassier L, Chung JJ, et al. Cellular localization of endothelin-1 and increased production in liver injury in the rat: Potential for autocrine and paracrine effects on stellate cells. Hepatology 1998;27:472-80

99 Shao R, Rockey DC. Regulation of endothelin-1 synthesis by endothelin-converting enzyme-1 during wound healing. J Biol Chem 1999;274:3228-34

100 Mallat A, Fouassier L, Preaux AM, et al. Growth inhibitory properties of endothelin-1 in human hepatic myofibroblastic lto cells. An endothelin B receptor-mediated pathway. J Clin Invest 1995;96:42-9.

101 Mallat A, Preaux AM, Serradeil-Le GC, et al. Growth inhibitory properties of endothelin-1 in activated human hepatic stellate cells: a cyclic adenosine monophosphate-mediated pathway. Inhibition of both extracellular signal-regulated kinase and c-Jun kinase and upregulation of endothelin B receptors. J Clin Invest 1996;98:2771-8.

102 Gandhi CR, Stephenson K, Olson MS. Endothelin, a potent peptide agonist in the liver. J Biol Chem 1990;265:17432-5.

103 Sogni P, Moreau R, Gomola A, et al. Beneficial hemodynamic effects of bosentan, a mixed $E T(A)$ and $E T(B)$ receptor antagonist, in portal hypertensive rats. Hepatology 1998;28:655-9.

104 Reichen J, Gerbes AL, Steiner M, et al. The effect of endothelin and its antagonist Bosentan on hemodynamics and microvascular exchange in cirrhotic rat liver. J Hepatol 1998;28:1020-30.

105 Kojima H, Yamao J, Tsujimoto T, et al. Mixed endothelin receptor antagonist, SB209670, decreases portal pressure in biliary cirrhotic rats in vivo by reducing portal venous system resistance. $J$ Hepato 2000;32:43-50

106 Poo JL, Jimenez W, Maria MR, et al. Chronic blockade of endothelin receptors in cirrhotic rats: hepatic and hemodynamic effects. Gastroenterology 1999;116:161-7.

107 Moncada S, Higgs A. The L-arginine-nitric oxide pathway. N Engl J Med 1993;329:2002-12

108 Wiest R, Groszmann RJ. Nitric oxide and portal hypertension: its role in the regulation of intrahepatic and splanchnic vascular resistance. Semin Liver Dis 1999;19:411-26.
109 Sessa WC. The nitric oxide synthetase family of proteins. J Vasc Res 1994:31:131-43.

110 Mittal MK, Gupta TK, Lee FY, et al. Nitric oxide modulates hepatic vascular tone in normal rat liver. Am J Physiol 1994;267:G416-22.

111 Shah V, Haddad FG, Garcia-Cardena G, et al. Liver sinusoidal endothelial cells are responsible for nitric oxide modulation of resistance in the hepatic sinusoids. J Clin Invest 1997;100:2923-30.

112 Tran-Thi TA, Kawada N, Decker K. Regulation of endothelin-1 action on the perfused rat liver. FEBS Lett 1993;318:353-7.

113 Gupta TK, Toruner M, Chung MK, et al. Endothelial dysfunction and decreased production of nitric oxide in the intrahepatic microcirculation of cirrhotic rats. Hepatology 1998;28:926-31.

114 Rockey DC, Chung JJ. Reduced nitric oxide production by endothelial cells in cirrhotic rat liver: endothelial dysfunction in portal hypertension. Gastroenterology 1998;114:344-51.

115 Shah V, Toruner M, Haddad FG, et al. Impaired endothelial nitric oxide synthase activity associated with enhanced caveolin binding in experimental cirrhosis in the rat. Gastroenterology 1999;117:1222-8.

116 Rockey DC, Chung JJ. Inducible nitric oxide synthase in rat hepatic lipocytes and the effect of nitric oxide on lipocyte contractility. J Clin Invest 1995:95: 1 199-206.

117 Rockey DC, Chung JJ. Regulation of inducible nitric oxide synthase and nitric oxide during hepatic injury and fibrogenesis. Am J Physiol 1997;273:G124-30

118 Bilzer M, Paumgartner G, Gerbes AL. Prolonged antagonism of adrenergic vasoconstriction in the rat liver by atrial natriuretic peptide. Gastroenterology 1995;108:803-11.

119 Gorbig MN, Gines P, Bataller R, et al. Atrial natriuretic peptide antaginizes endothelin-induced calcium increase and cell contraction in cultured human hepatic stellate cells. Hepatology 1999;30:501-9.

120 Guevara M, Gines P, Jimenez W, et al. Increased adrenomedullin levels in cirrhosis: Relationship with hemodynamic abnormalities and vasoconstrictor systems. Gastroenterology 1998;1 14:336-43

121 Fernandez-Rodriguez CM, Prada IR, Prieto J, et al. Circulating adrenomedullin in cirrhosis: relationship to hyperdynamic circulation. $J$ Hepatol 1998;29:250-6.

122 Gorbig MN, Gines P, Bataller R, et al. Human hepatic stellate cells secrete adrenomedullin: potential autocrine factor in the regulation of cell contractility. J Hepatol 2001;34:222-9.

123 Kawada N, Inove M. Effect of adrenomedullin on hepatic pericytes (stellate cells) of the rat. FEBS Lett 1994:356:109-13.

124 Chun TH, Itoh H, Ogawa Y, et al. Shear stress augments expression of C-type natriuretic peptide and adrenomedullin. Hypertension 1997;29:1296-302.

125 Wiest R, Tsai MH, Groszmann RJ. Octreotide potentiates PKC-dependen vasoconstrictors in portal-hypertensive and control rats. Gastroenterology $2001 ; 120: 975-83$

126 Reynaert H, Vaeyens F, Qin H, et al. Somatostatin suppresses endothelin-1 induced rat hepatic stellate cell contraction via somatostatin receptor subtype 1. Gastroenterology 2001;121:915-30.

127 Mashiba S, Mochida S, Ishikawa K, et al. Inhibition of hepatic stellate cell contraction during activation in vitro by vascular endothelial growth factor in association with upregulation of FLT tyrosine kinase receptor family, FLT-1. Biochem Biophys Res Commun 1999;258:674-8.

128 Kawada N, Klein H, Decker K. Eicosanoid-mediated contractility of hepatic stellate cells. Biochem J 1992:285(Pt 2):367-71.

129 Kawada N, Kuroki T, Uoya M, et al. Smooth muscle alpha-actin expression in rat hepatic stellate cell is regulated by nitric oxide and cGMP production. Biochem Biophys Res Commun 1996;229:238-42.

130 Titos E, Claria J, Bataller R, et al. Hepatocyte-derived cysteinyl leukotrienes modulate vascular tone in experimental cirrhosis. Gastroenterology 2000;1 19:794-805.

131 Bataller R, Nicolas JM, Gines P, et al. Arginine vasopressin induces contraction and stimulates growth of cultured human hepatic stellate cells. Gastroenterology 1997;113:615-24.

132 Bosch J, Arroyo V, Betrui A, et al. Hepatic hemodynamics and the renin-angiotensin system in cirrhosis. Gastroenterology 1980;78:92-9

133 Matsusaka T, Ichikawa I. Biological functions of angiotensin and its receptors. Annu Rev Physiol 1997;59:395-412

134 Bataller R, Gines P, Nicolas JM, et al. Angiotensin II induces contraction and proliferation of human hepatic stellate cells. Gastroenterology 2000;118:1149-56.

135 Fernandez-Rodriguez CM, Prieto J, Quiroga J, et al. Plasma levels of substance $P$ in liver cirrhosis: relationship to the activation of vasopressor systems and urinary sodium excretion. Hepatology 1995;21:35-40.

136 Chu CJ, Lee FY, Wang SS, et al. Hyperdynamic circulation of cirrhotic rats: role of substance $P$ and its relationship to nitric oxide. Scand J Gastroenterol 1997;32:841-6.

137 Takemura S, Kawada N, Hirohashi K, et al. Nucleotide receptors in hepatic stellate cells of the rat. FEBS Lett 1994;354:53-6.

138 Thimgan MS, Yee HF. Quantitation of rat hepatic stellate cell contraction: stellate cells' contribution to sinusoidal resistance. Am J Physiol 1999;277: G137-43

139 Friedman SL, Maher JJ, Bissell DM. Mechanisms and therapy of hepatic fibrosis: report of the AASLD Single Topic Basic Research Conference. Hepatology 2000;32:1403-8.

140 De Gottardi A, Shaw S, Sagesser H, et al. Type A, but not type B, endothelin receptor antagonists significantly decrease portal pressure in portal hypertensive rats. J Hepatol 2000;33:733-7.

141 Cho JJ, Hocher B, Herbst H, et al. An oral endothelin-A receptor antagonist blocks collagen synthesis and deposition in advanced rat liver fibrosis. Gastroenterology 2000;1 18: 1169-78. 
142 Failli P, DeFranco RM, Caligiuri A, et al. Nitrovasodilators inhibit platelet-derived growth factor-induced proliferation and migration of activated human hepatic stellate cells. Gastroenterology 2000; 1 19:479-92

143 Yu Q, Shao R, Qian HS, et al. Gene transfer of the neuronal NO synthase isoform to cirrhotic rat liver ameliorates portal hypertension. J Clin Invest 2000;105:741-8

144 Schneider AW, Kalk JF, Klein CP. Effect of losartan, an angiotensin II receptor antagonist, on portal pressure in cirrhosis. Hepatology 1999:29:334-9.

145 Gonzalez-Abraldes J, Albillos A, Banares R, et al. Randomized comparison of long-term losartan versus propranolol in lowering prortal pressure in cirrhosis. Gastroenterology 2001;121:382-8.
146 Iwamoto H, Nakamuta M Tada S, et al. A pl60ROCK-specific inhibitor, Y-27632, attenuates rat hepatic stellate cell growth. J Hepatol 2000;32:762-70.

147 Tangkijvanich P, Tam SP, Yee HFJ. Wound-induced migration of rat hepatic stellate cells is modulated by endothelin-1 through rho-kinase-mediated alterations in the acto-myosin cytoskeleton. Hepatology 2001;33:74-80

148 Fort J, Oberti F, Pilette C, et al. Antifibrotic and hemodynamic effects of the early and chronic administration of octreotide in two models of liver fibrosis in rats. Hepatology 1998;28:1525-31.

149 Reynaert H, Vaeyens F, Rombouts K, et al. Effect of somastatin-14 on extracellular matrix expression by activated rat hepatic stellate cells. J Hepatol $2001 ; 34($ Suppl):6.

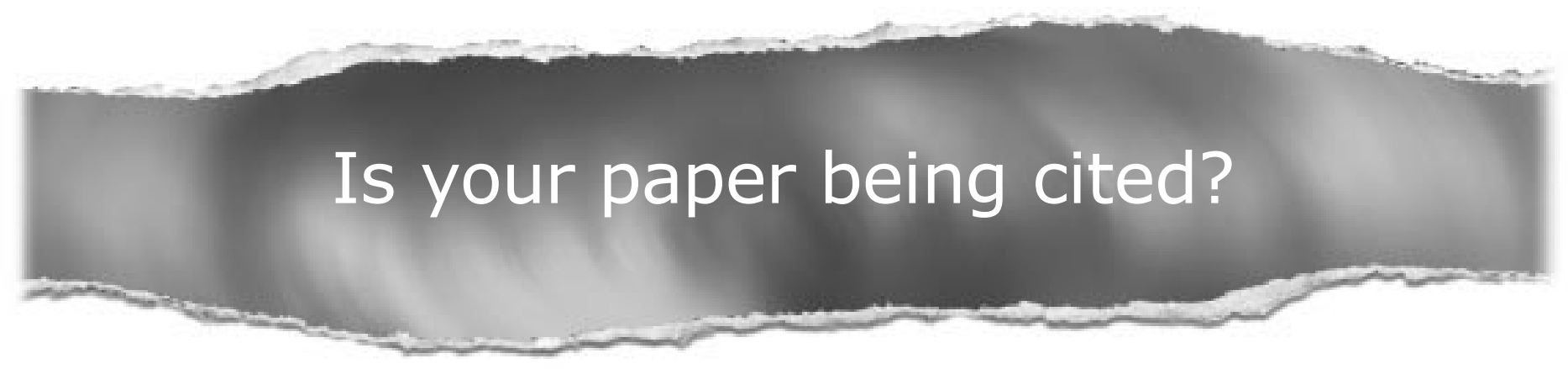

\section{CiteTrack service}

CiteTrack will alert you by email whenever new content in Gut or a participating journal is published

that matches criteria you want to track

Topics: Tell CiteTrack which words or subjects to watch for in new content

Authors: Be alerted whenever key authors you are following publish a new paper

Articles: Know whenever a paper of interest to you is referenced by another paper

\section{www.gutjnl.com}

